\title{
Analysis on Protection of Consumer Rights and Interests from the Perspective of Cross-border Electronic Commerce
}

\author{
Liying Ji \\ College of Economics and Trade, Haikou University of Economics, Haikou Hainan, 571157, China
}

Keywords: cross-border electronic commerce; consumer rights and interests; legal problem; protection countermeasure

\begin{abstract}
This is an economic globalization era, the era of rapid internet information development and modern civilization era in which the society is governed according to laws. Hence, each industry in the society should follow the three laws of era development, think how to stand in the social market rationally and legally and better serve consumers and objects. Cross-border electronic commerce is the emerging force for current social development. In the process of developing and expanding the strength, the protection of consumer rights and interests must be conducted well. In this paper, various legal problems in protection of consumer rights and interests are simply thought from the perspective of cross-border electronic commerce, and the protection countermeasures for rights and interests of cross-border electronic commerce consumers are proposed.
\end{abstract}

\section{Introduction}

As workers of cross-border electronic commerce, we have received strong support of national policy in recent ten years. As market competition becomes increasingly fierce, we also deeply feel the fierce of market competition and the importance of consumers. There are more and more import-type cross-border electronic commerce workers. Meanwhile, many behaviors infringing consumer rights and interests appear, because relevant laws of cross-border electronic commerce consumers lack seriously technicality and uniformity. Thus, many difficulties are confronted to safeguard legal rights of consumers. Therefore, we should first clearly know the main legal problems about protection of consumer rights and interests.

\section{Legal Problems of Cross-border Electronic Commerce in Protection of Consumer Rights and Interests}

At present, electronic commerce field develops rapidly. Cross-border electronic commerce even has become the development mainstream in the industry. But, we are also faced with numerous problems during operating the business about cross-border electronic commerce. For example, the right safeguarding method and cost for consumers become larger and larger. As a result, our development prospect becomes fuzzy. The large number of hidden problems and network false advertising problems prove current right safeguarding measures are seriously insufficient. Judging from practical operation, the workers of cross-border electronic commerce will touch the following legal problems in the work of consumer rights and interests protection.

\subsection{Fundamental rights of consumers}

Fundamental rights of consumers are the root of right safeguarding work, including personal property security right, independent option right, the right to be informed, privacy right, the right of fair trade, the right of claim, the right to be respected, supervision right and so on. Of course, as internet information field becomes developed gradually, "the right to comment" has become a new right and right safeguarding means of consumers. So, the workers are faced with very complex environment during protecting consumer rights and interests. The latest consumer comment right 
protection is taken for example. China is a country under the rule of law, and freedom of expression is a fundamental right. So, the constitution specifies that people enjoy the right to comment which is the right and interest of freedom of expression. In the field of cross-border electronic commerce, consumers' right to comment is especially important. This is because of paperless and virtuality features of electronic commerce. Consumers can evaluate the products and services by the right to comment. Especially in the field of cross-border electronic commerce, the application value of the right to comment becomes higher. Consumers cannot seek for the solutions through spanning the national boundaries and complaining to the government agencies or courts in other countries. The right to comment solves this issue. It becomes the important basis for consumers to purchase products. With the double protection of national and international laws, the possibility of infringing consumer rights and interests becomes lower and lower.

\subsection{Cross-border e-payment problem}

E-payment is convenient and fast, and it is the most effective transaction channel for cross-border electronic commerce to connect consumers. As e-payment functions gradually become rich, more and more legal problems also appear. They may affect consumers' basic rights and interests. Once the problems happen, the liability becomes fuzzy. The contradictions between us and consumers also appear. For example, in accordance with the provisions of Support Service Management Method of Non-financial Institutions, the payment institutions do not enjoy the ownership of customers' excess reserve. How to distribute the fruits? This is a key problem. The fruit is the interest generated by trust property with the nature of excess reserve, and decides interest belonging problem of customers' excess reserve. In principle, the payment institutions do not enjoy the ownership of interests generated by the excess reserve. Thus, some cross-border electronic commerce platforms make the interests generated by the excess reserve belong to the payment institutions, which does not comply with the theory of law and goes against the Method. Besides, it infringes consumers' basic rights and interests to certain degree.

\subsection{Cross-border dispute settlement problem}

Consumers may have disputes with cross-border electronic commerce platforms during cross-border consumption, which is common in work. Such disputes often refer to relevant content of Consumer Rights and Interests Protection. Generally speaking, we trade with consumers via long distance. If consumer rights and interests are infringed, the cost in safeguarding the rights and interests becomes high for the cross-border reason. Consumers are often helpless and have to undertake the consequences by themselves. Thus, the dispute settlement mechanism cannot adapt to the development of cross-border electronic commerce. The Online Dispute Resolution can replace traditional dispute settlement mechanism to certain degree. It resolves disputes through online network and makes the network become the non-court and absolutely fair third-party role. From the perspective of electronic commerce contract, such practice can absorb more cross-border electronic commerce platforms and cross-border consumers. But, we have to admit that, Chinese government and relevant legal mechanisms do not involve such online dispute resolution. Even there is such online dispute resolution, it pays excessive attention to protecting merchant interests and involves various advertising expenses and membership fees. Such rich interest return cannot make right and interest protection policy of cross-border electronic commerce platforms and relevant consumers tend to consumers. But at present, consumers really need such a relatively independent and fair platform with the right of speech. The online dispute settlement mechanism should be constructed from the perspective of absolutely fair right safeguarding so that the judicial organ has the chance to protect he parties well.

\section{Effective Countermeasures to Improve Consumer Rights and Interests Protection of Cross-border Electronic Commerce}

In the work of cross-border electronic commerce, the protection of consumer rights and interests is 
very weak. In combination of the above right safeguarding problems based on laws, it is believed that cross-border electronic commerce platforms should think over problems from the aspect of consumer rights and interests protection, propose a series of effective countermeasures to improve consumer rights and interests, and establish rational and legal right and interest protection rules and systems for electronic commerce consumers.

\subsection{Basic protection of consumers' consumption right}

First of all, the basic protection work for consumers' consumption right should be done well, which should be considered first by cross-border electronic commerce platforms. Firstly, relatively thorough register, authentication, examination and approval system should be established. In accordance with Network Transaction Management Method issued in 2014, the third-party supervision platform with relatively complete legal content must be established. It can be used to legally manage each electronic commerce platforms, such as the hot "WeChat" platform. It can help consumers safeguard rights by cooperating with industrial and commercial registration as well as government agency. Relevant consumer right protection mechanism can be handled by the form of individual business. In the process of safeguarding rights, consumers can directly choose to complain to the competent department so as to effectively increase right safeguarding channels.

Secondly, consumers' right to know should be protected. According to Law on Protection of the Rights and Interests of Consumers, online information disclosure system should be established. On this basis, it is required to refer to EU's regulations about electronic commerce and consciously expand the scope of information disclosure. For example, this information disclosure mechanism requires cross-border electronic commerce workers to actively disclose their qualification and credit information. For example, in pharmaceuticals industry, many medicines in domestic pharmaceutical market are not accepted by Chinese people. They will choose cross-border purchase of medicines. Then, cross-border electronic commerce operators must make their enterprise qualification information and medicine quality information public to consumers so as to solve consumers' doubts and create credit conditions for consumers. This can evade the infringement of consumer rights and interests. Therefore, from the legal perspective, we have the obligation to make enterprise qualification and business qualification public, including commodity marketing permit.

Thirdly, the right to comment should be protected. The right to comment is a new right of consumers who apply network. But we often see cross-border electronic commerce platforms infringe, deceive consumers, and modify good reputation rate and even the comments in order to achieve the good reputation rate. This is obviously adverse to the protection of consumer rights and interests. So, this right should be added in the new Electronic Commerce Law. Cross-border electronic commerce platforms must assist laws to balance and coordinate consumers' right to comment and merchants' reputation right, supervise and guarantee consumers' effective exercise of right to comment after buying products. Meanwhile, consumers' right application process should be further specified on the basis of Law on Protection of the Rights and Interests of Consumers. If consumers infringe operators' reputation right, the operators also have the right to require consumers to compensate and apologize. Moreover, consumers' subjective and real comments should be respected, and the right to comment should be protected.

\subsection{Basic protection of cross-border e-payment right and interest}

Cross-border e-payment is convenient and simple, but it involves numerous legal problems. To legally and effectively protect consumer rights and interests, we need to improve excess reserve management mechanism and objectively specify the inherent legal nature of excess reserve. As a trust property, it should comply with the practice connotation of trusteed object. The excess reserve is generated in electronic commerce. We should give consumers certain right of rescission to avoid fraudulent conduct of operators. Besides, cross-border electronic commerce platforms have no right to embezzle the excess reserve for other purposes, because it will generate huge fruits. From the perspective of theory of law, the fruits should belong to consumers. But in fact, it is hard to generate 
fruits in practical consumption activity, because the amount managed by the payment institution is very small, so the fruits generally exist in the theory. For consumers, few people will consider such interests belonging to them. If the excess reserve generates the fruits, how to allocate the fruit earnings? Its ownership still belongs to consumers, or such money can be used as the right and interest protection fund for consumers. Once consumer rights and interests are infringed, it may be used for compensation.

\subsection{Ways to solve consumer right and interest disputes of cross-border electronic commerce}

The ways to solve right and interest disputes of cross-border electronic commerce consumers should be mainly considered in our daily work. Since some traditional and inherent dispute mechanisms have been no longer suitable for the development need of cross-border electronic commerce, the new dispute resolution methods should be sought in terms of consumer dispute settlement mechanism construction.

Firstly, the third-party platform appealing mechanism should be established. Because consumers' right and interest disputes are common in daily operation, we are in different environment with consumers, so the difficult in safeguarding rights exists. Sometimes, consumers have to suffer hidden loss and cannot complain. Nowadays, the special third-party platform appealing mechanism should be provided for consumers to solve the problems which cannot be solved through negotiation and communication through the third-party platform. Under special conditions, the dependence and restriction relation with consumers should be established on the basis of the inherent information, fund and resource advantages of cross-border electronic commerce. Consumers' loss part should be first compensated. Then, cross-border electronic commerce operators should be compensated. In fact, such appealing mechanism of cross-border electronic commerce platform may be between electronic commerce platform operators and consumers. The basic rights and interests of operators also should be included in the scope of consumer rights and interests protection. This contributes to coordinating the relation between electronic commerce platform operators and consumers so that we can have more opportunities to protect consumers' legal interests.

Secondly, online dispute settlement mechanism based on innovation thought should be established and improved. If this settlement mechanism works, it can effectively relieve the disputes and working pressure between us and consumers. In practice, as early as 2000, International Organization of Consumers Unions proposed such online dispute settlement mechanism. For China's cross-border electronic commerce field, it effectively enriches and supplements the third-party appealing platform. The arbitrators of this new mechanism are responsible for answering customers' questions online and providing guarantee and arbitration results based on legal procedures. Objectively speaking, it follows arbitrator system of arbitration committee, so both parties are willing to submit the disputes to online dispute settlement mechanism platform, in the hope of finally reaching the consensus, and compulsorily executing dispute resolution method based on legal procedures and contents.

\section{Summary}

As cross-border electronic commerce workers, we deeply know various problems will be confronted in the cross-border operation process. Especially in the internet environment, this issue becomes complex and bewildering. In the future, we should actively combine with local legal department, take active part in legal research and protection of consumer rights and interests and create the beneficial environment for making consumer rights and interests protection legal and rational.

\section{References}

[1] Guo Wenjing, Ways to Improve Consumer Rights and Interests Protection from the Perspective of Cross-border Electronic Commerce, Journal of Sichuan Provincial Correspondence Institute for Administrators, 2017(4):114-116. 
[2] Yang Yang, Research on the Legal Supervision of Third-party Cross-border Electronic Payment Services, Journal of Regional Financial Research, 2016(2):79-85.

[3] Research group of Shanghai Industry and Commerce Bureau. Study on Current Situation of Cross-border Electronic Commerce Development and Supervision Countermeasures, Study on China Administration for Industry \& Commerce, 2015(10):38-42.

[4] Xiao Wen, Research on Application Problems of Contract Laws of Cross-border Consumers, Southwest University of Political Science and Law, 2016. 